\title{
Solution Properties of Amylose Tris(Phenylcarbamate): Local Conformation and Chain Stiffness in 1,4-Dioxane and 2-Ethoxyethanol
}

\author{
By Ken TERAO, ${ }^{1, *}$ Taichi FUJII, ${ }^{1}$ Maiko TSUDA, ${ }^{1}$ \\ Shinichi KITAMURA, ${ }^{2}$ and Takashi NORISUYE ${ }^{1}$
}

Light and small-angle X-ray scattering, sedimentation equilibrium, viscosity, circular dichroism, and infrared absorption measurements have been made on 1,4-dioxane (DIOX) and 2-ethoxyethanol (2EE) solutions of seven amylose tris(phenylcarbamate) samples ranging in molecular weight from $2 \times 10^{4}$ to $3 \times 10^{6}$. Analyses of gyration radius, scattering function, and intrinsic viscosity data in terms of the wormlike chain model yield Kuhn segment lengths of $22 \pm 2 \mathrm{~nm}$ and $16 \pm 2 \mathrm{~nm}$ in DIOX and 2EE, respectively, and a contour length per residue of $0.33 \pm 0.02 \mathrm{~nm}$ in both, showing that the amylose derivative chain has high stiffness and a contour length slightly shorter than the known value $0.37-0.40 \mathrm{~nm}$ for amylosetriesters in the crystalline state. These results are consistent with the intramolecular hydrogen bonding between the $\mathrm{C}=\mathrm{O}$ and $\mathrm{NH}$ groups of the neighbor repeating units detected by infrared absorption and also with the locally regular (or helical) conformation indicated by circular dichroism.

KEY WORDS: Amylose Tris(Phenylcarbamate) / Light Scattering / SAXS / Intrinsic Viscosity / Wormlike Chain / Hydrogen Bonding /

Dilute solutions of amylose tris(phenylcarbamate) (ATPC), whose chemical structure is illustrated in Figure 1, have widely been studied due to the good solubility in various solvents including some theta solvents. ${ }^{1-12}$ This derivative behaves as a stiff chain in solution in contrast to the high flexibility of amylose. ${ }^{13,14}$ The contrast suggests that intramolecular hydrogen bonding between neighboring $\mathrm{C}=\mathrm{O}$ and $\mathrm{NH}$ groups is responsible for the stiffness of the ATPC chain. If indeed formed, such hydrogen bonds should affect the local conformation of ATPC and the contour length $h$ per repeat unit, i.e., the helix pitch per residue (provided the chain is helical), in addition to the global conformation or the chain stiffness. The local structure of this amylose derivative is also a subject in efficient chiral separation. ${ }^{15,16}$

Despite such importance of $h$, however, we find no report on its experimental determination for ATPC in the literature except the very early work of Burchard, ${ }^{8}$ who, analyzing gyration radius data in terms of the wormlike chain, ${ }^{17}$ estimated $h$ in the dioxane-methanol mixed theta solvent to be $0.26 \mathrm{~nm}$, a value about one-half that of cellulose tris(phenylcarbamate). The Kuhn segment length $\lambda^{-1}$ he obtained was as large as $46 \mathrm{~nm}$. Later, in their characterization work on ATPC, Pfannemüller et al. ${ }^{11}$ estimated $\lambda^{-1}$ to be $18-26 \mathrm{~nm}$ in $1,4-$ dioxane (DIOX) assuming $h=0.37 \mathrm{~nm}$ (the helix pitch per residue based on the crystal structure of amylose tribenzoate ${ }^{18}$ ). These estimates of $\lambda^{-1}$ by the two groups are at variance depending strongly on $h$.

For the understanding of the conformational characteristics, local and global, of ATPC in solution, unequivocal determi-

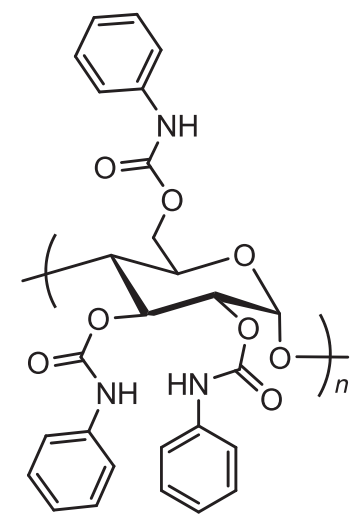

Figure 1. Chemical structure of amylose tris(phenylcarbamate) (ATPC).

nation of the wormlike-chain parameters $\left(h\right.$ and $\left.\lambda^{-1}\right)$ is almost mandatory in a solvent in which intramolecular hydrogen bonds between $\mathrm{C}=\mathrm{O}$ and $\mathrm{NH}$ groups are detected by experiment. Thus, in the present work, we made light scattering, sedimentation equilibrium, synchrotron radiation small-angle X-ray scattering (SAXS), viscosity, circular dichroism (CD), and infrared absorption (IR) measurements on ATPC samples in DIOX and 2-ethoxyethanol (2EE). These solvents allowed us to obtain information on the (possible) helical conformation of the ATPC molecule and the intramolecular hydrogen bonding from $\mathrm{CD}$ and IR, respectively. The estimation of the wormlike-chain parameters from scattering and viscosity data are described below along with these findings from spectroscopy.

\footnotetext{
${ }^{1}$ Department of Macromolecular Science, Graduate School of Science, Osaka University, 1-1, Machikaneyama-cho, Toyonaka 560-0043, Japan ${ }^{2}$ Graduate School of Life and Environmental Sciences, Osaka Prefecture University, Gakuen-cho, Nakaku, Sakai 599-8531, Japan

*To whom correspondence should be addressed (Tel: +81-6-6850-5459, Fax: +81-6-6850-5461, E-mail: kterao@chem.sci.osaka-u.ac.jp).
} 


\section{EXPERIMENTAL}

\section{Preparation of ATPC Samples}

Seven amylose samples with narrow molecular-weight distribution and no branching ${ }^{19-22}$ were enzymatically synthesized by the previously reported method ${ }^{19}$ using potato phosphorylase (EC 2.4.1.1.) or supplied by Ezaki Glico Co., Ltd. Their weight-average molecular weights $M_{\mathrm{w}}$ ranged from $6 \times 10^{3}$ to $1 \times 10^{6}$ and their weight to number-average molecular weight ratios $M_{\mathrm{w}} / M_{\mathrm{n}}$ were less than 1.2 when estimated by SEC-LS (size exclusion chromatography combined with multiangle or low-angle light scattering and refractometry). ATPC samples were synthesized from the amylose samples and phenylisocyanate. The typical procedures were as follows.

Each amylose sample $(3.0 \mathrm{~g})$ and $\mathrm{LiCl}(3.0 \mathrm{~g})$ dried in vacuum at $130{ }^{\circ} \mathrm{C}$ for several hours were dissolved in $N, N^{\prime}$ dimethylacetoamide $\left(30 \mathrm{~cm}^{3}\right)$ at $110^{\circ} \mathrm{C}$ under $\mathrm{N}_{2}$ atmosphere. Pyridine $\left(100 \mathrm{~cm}^{3}\right)$ and an excess amount $(20 \mathrm{~g}, 0.17 \mathrm{~mol})$ of phenylisocyanate were added to the mixture and stirred for $12 \mathrm{~h}$ at $110^{\circ} \mathrm{C}$. The product was reprecipitated twice from an acetone solution into methanol to remove foreign substances such as unreacted phenylisocyanate and $\mathrm{LiCl}$. $\mathrm{LiCl}$ and phenylisocyanate (Wako and Tokyo Kasei, respectively) were used without further purification. $N, N^{\prime}$-dimethylacetoamide, pyridine, DIOX, and 2EE (Wako) were purified by fractional distillation over $\mathrm{CaH}_{2}$.

The resultant samples were further purified by fractional precipitation with acetone as a solvent and methanol as a precipitant, and appropriate middle fractions from the respective ATPC samples were reprecipitated into methanol. They were designated as ATPC20K, ATPC50K, АTPC200K, ATPC300K, ATPC500K, ATPC800K, and ATPC3M based on the molecular weights. The degree of substitution was estimated to be 3.0-3.1 for all these fractions from the mass ratio of carbon to nitrogen determined by elemental analysis. It was also determined for ATPC20K and ATPC50K to be $3.0 \pm$ 0.1 by ${ }^{1} \mathrm{H}$ NMR (JEOL GSX-400 NMR spectrometer) in acetone- $d_{6}$ at $30^{\circ} \mathrm{C}$. Thus we concluded that the three hydroxyl groups on each glucose unit of amylose were fully substituted to phenylcarbamate.

\section{Light Scattering}

Light scattering measurements were made for five high molecular weight ATPC samples in DIOX and $2 \mathrm{EE}$ at $25^{\circ} \mathrm{C}$ on a Fica-50 light scattering photometer with vertically polarized incident light of 436 or 546-nm wavelength $\lambda_{0}$ in an angular range from $22.5^{\circ}$ to $150^{\circ}$. The instrument was calibrated with benzene at $25^{\circ} \mathrm{C}$ with the Rayleigh ratio for the unpolarized incident light at $90^{\circ}$ taken as $4.65 \times 10^{-5} \mathrm{~cm}^{-1}$ at $436 \mathrm{~nm}$ and $1.61 \times 10^{-5} \mathrm{~cm}^{-1}$ at $546 \mathrm{~nm},{ }^{23}$ the depolarization ratio of this liquid was determined to be 0.44 and 0.41 for 436 and $546 \mathrm{~nm}$, respectively, by the method of Rubingh and $\mathrm{Yu}^{24}$

The square-root plots ${ }^{25}$ of $\left(K c / R_{\theta}\right)^{1 / 2} v s . \sin ^{2}(\theta / 2)$ and $v s . c$ were used to determine $M_{\mathrm{w}}$, the second virial coefficient $A_{2}$, and the z-average mean-square radius of gyration $\left\langle S^{2}\right\rangle_{z}$, where
$K, c$, and $R_{\theta}$ denote the optical constant, the polymer mass concentration, and the excess reduced scattering intensity at scattering angle $\theta$, respectively.

Polymer solutions and the solvents were made optically clean by centrifugation at about $3 \times 10^{4}$ gravities for $80 \mathrm{~min}$ at $25^{\circ} \mathrm{C}$. Each of them was transferred into a cylindrical light scattering cell $(22 \mathrm{~mm}$ i.d.) with a stainless steel tube $(0.5 \mathrm{~mm}$ i.d.). The cell and the tube had been cleaned by acetone filtered through a $0.02 \mu \mathrm{m}$ membrane filter.

The specific refractive index increments $\partial n / \partial c$ for ATPC20K and ATPC3M in DIOX and for ATPC800K in $2 \mathrm{EE}$ at $25^{\circ} \mathrm{C}$ were determined using a modified Schulz-Cantow type differential refractometer. The results at $\lambda_{0}=436,546$, and $633 \mathrm{~nm}$ were $0.160,0.148,0.143 \mathrm{~cm}^{3} \mathrm{~g}^{-1}$, respectively, for ATPC3M in DIOX; the values for ATPC20K in DIOX were about $2 \%$ larger than these at the corresponding wavelengths. For ATPC $800 \mathrm{~K}$ in $2 \mathrm{EE}$, we obtained $\partial n / \partial c=0.173,0.159$, $0.153 \mathrm{~cm}^{3} \mathrm{~g}^{-1}$ for $\lambda_{0}=436,546$, and $633 \mathrm{~nm}$, respectively.

\section{Small-angle X-ray Scattering (SAXS)}

Scattering intensities at $\theta$ and at $\lambda_{0}=0.10 \mathrm{~nm}$ were measured for ATPC20K and ATPC50K both in DIOX and in $2 \mathrm{EE}$ at $25^{\circ} \mathrm{C}$ using a Rigaku R-AXIS IV++ or an R-AXIS VII imaging plate detector at the BL40B2 beamline in SPring-8; the camera length was set to be $1500 \mathrm{~mm}$. A $1.5 \mathrm{~mm} \phi$ quartz capillary filled with each test solution was set to the cell holder whose temperature was controlled with a circulating waterbath. The beam center of the imaging plate and the camera length were determined accurately from the Bragg reflection of powdery lead stearate. The scattering intensities for each solution or solvent were corrected for the incident-beam intensity and the transmittance, both determined using the ionic chambers installed at the upper and lower ends of the capillary. The excess scattering intensity $I_{\theta}$ was analyzed using the square-root plots ${ }^{25}$ of $\left(c / I_{\theta}\right)^{1 / 2} v s . \sin ^{2}(\theta / 2)$ and $v s . c$ to determine $\left\langle S^{2}\right\rangle_{\mathrm{Z}}$ and $P(k)$ (the particle scattering function) at the absolute value of the scattering vector $k$.

\section{Sedimentation Equilibrium}

Sedimentation equilibrium measurements were made for samples ATPC20K and ATPC50K in DIOX at $25^{\circ} \mathrm{C}$ in a Beckman Optima XL-I analytical ultracentrifuge to determine $M_{\mathrm{w}}, A_{2}$, and the z-average molecular weight $M_{\mathrm{z}}$ (see ref 26 for the experimental procedures and data analysis). The rotor speed was chosen to be $3 \times 10^{4}$ and $1.1 \times 10^{4} \mathrm{rpm}$ for ATPC20K and ATPC50K, respectively. The concentration profile in each 12-mm double sector cell was obtained from the Rayleigh interference patterns observed with a diode laser of $\lambda_{0}=675 \mathrm{~nm}$. The $\partial n / \partial c$ at this $\lambda_{0}$ was estimated from the above-mentioned data at other $\lambda_{0}$ with the aid of $\partial n / \partial c v s . \lambda_{0}{ }^{-2}$ plot. The partial specific volume was determined for ATPC $20 \mathrm{~K}$ and ATPC 50K in DIOX at $25^{\circ} \mathrm{C}$ to be 0.714 and $0.724 \mathrm{~cm}^{3} \mathrm{~g}^{-1}$, respectively, using an Anton Paar DMA 5000 densitometer.

\section{Viscometry}

Viscosity measurements in DIOX and in $2 \mathrm{EE}$ at $25^{\circ} \mathrm{C}$ were 
Table I. Numerical results from light scattering, SAXS, viscosity, and SEC-LS measurements on ATPC samples in 1,4-dioxane (DIOX) and 2-ethoxyethanol (2EE) at $25^{\circ} \mathrm{C}$

\begin{tabular}{|c|c|c|c|c|c|c|c|c|c|c|c|}
\hline \multirow[b]{2}{*}{ Sample } & \multirow[b]{2}{*}{$M_{\mathrm{w}} / 10^{4}$} & \multicolumn{4}{|c|}{ in DIOX } & \multicolumn{4}{|c|}{ in $2 E E$} & \multirow[b]{2}{*}{$M_{\mathrm{z}} / M_{\mathrm{w}}$} & \multirow[b]{2}{*}{$M_{\mathrm{w}} / M_{\mathrm{n}}$} \\
\hline & & $\begin{array}{c}\left\langle S^{2}\right\rangle_{z}^{1 / 2} \\
(\mathrm{~nm})\end{array}$ & $\begin{array}{c}10^{4} A_{2} \\
\left(\mathrm{~cm}^{3} \mathrm{~mol} \mathrm{~g}^{-2}\right)\end{array}$ & $\begin{array}{c}{[\eta]} \\
\left(\mathrm{cm}^{3} \mathrm{~g}^{-1}\right)\end{array}$ & $k^{\prime}$ & $\begin{array}{c}\left\langle S^{2}\right\rangle_{z}^{1 / 2} \\
(\mathrm{~nm})\end{array}$ & $\begin{array}{c}10^{4} A_{2} \\
\left(\mathrm{~cm}^{3} \mathrm{~mol} \mathrm{~g}^{-2}\right)\end{array}$ & $\begin{array}{c}{[\eta]} \\
\left(\mathrm{cm}^{3} \mathrm{~g}^{-1}\right)\end{array}$ & $k^{\prime}$ & & \\
\hline АТРC3M & $327^{a}$ & $99^{a}$ & $1.4^{\mathrm{a}}$ & 657 & 0.42 & $82^{a}$ & $1.2^{\mathrm{a}}$ & 409 & 0.41 & & \\
\hline ATPC800K & $76.5^{\mathrm{a}}$ & $44^{a}$ & $3.0^{\mathrm{a}}$ & 242 & 0.33 & $36^{a}$ & $2.3^{\mathrm{a}}$ & 144 & 0.42 & & $1.09^{d}$ \\
\hline ATPC500K & $47.9^{a}$ & $35^{a}$ & $2.0^{\mathrm{a}}$ & 176 & 0.35 & $30^{a}$ & $2.8^{\mathrm{a}}$ & 119 & 0.40 & & $1.08^{d}$ \\
\hline АТРС300K & $27.9^{a}$ & $24.5^{\mathrm{a}}$ & $2.2^{\mathrm{a}}$ & 113 & 0.37 & $22.0^{\mathrm{a}}$ & $3.7^{\mathrm{a}}$ & 83.6 & 0.40 & & $1.09^{d}$ \\
\hline ATPC200K & $18.9^{a}$ & $19.5^{\mathrm{a}}$ & $2.2^{\mathrm{a}}$ & 78.4 & 0.35 & $17.5^{\mathrm{a}}$ & $1.5^{\mathrm{a}}$ & 52.3 & 0.50 & & $1.11^{\mathrm{d}}$ \\
\hline ATPC50K & $5.48^{c}$ & $7.8^{\mathrm{b}}$ & $1.3^{\mathrm{c}}$ & 28.6 & 0.43 & $7.3^{b}$ & & 22.9 & 0.83 & $1.05^{\mathrm{c}}$ & \\
\hline ATPC20K & $1.87^{c}$ & $3.3^{b}$ & $7^{c}$ & 10.7 & 0.50 & $3.0^{\mathrm{b}}$ & & 8.8 & 1.1 & $1.09^{c}$ & \\
\hline
\end{tabular}

a Light scattering. ${ }^{b}$ SAXS. ${ }^{c}$ Sedimentation equilibrium. dSEC-LS in tetrahydrofuran at $30^{\circ} \mathrm{C}$.

carried out using a four-bulb low-shear capillary viscometer of the Ubbelohde type for ATPC3M in DIOX and conventional capillary viscometers for all ATPC samples in the two solvents. The Huggins plot, ${ }^{27}$ the Fuoss-Mead plot, ${ }^{28}$ and the Billmeyer $\operatorname{plot}^{29}$ were combined to determine the intrinsic viscosity $[\eta]$ and the Huggins constant $k^{\prime}$. The shear-rate effect on $[\eta]$ was negligible (less than 2\%) even for the highest $M_{\mathrm{w}}$ sample ATPC3M.

\section{Circular Dichroism}

Both CD and UV spectra for ATPC300K in DIOX and in $2 \mathrm{EE}$ at $25^{\circ} \mathrm{C}$ were recorded on a JASCO J720WO spectropolarimeter in the range of $\lambda_{0}$ between 210 and $280 \mathrm{~nm}$. The experimental conditions were as follows: a band-width of $10 \mathrm{~nm}$, a response time of $2 \mathrm{~s}$, a scanning rate of $20 \mathrm{~nm} / \mathrm{min}$, and five times accumulations. A rectangular quartz cell of 2-mm path length $(l)$ was set in a cell holder thermostated with a circulating waterbath. The molar extinction coefficient $\varepsilon$ and the molar circular dichroism $\Delta \varepsilon$ were calculated from the measured absorbance $A$ and ellipticity $\theta^{\prime}$ with

$$
\varepsilon=\frac{A M_{0}}{c l}, \quad \Delta \varepsilon=\frac{\theta^{\prime} M_{0}}{33 c l}
$$

where $M_{0}$ denotes the molar mass of the repeating unit of ATPC.

\section{Infrared Absorption (IR)}

IR spectra for ATPC $300 \mathrm{~K}$ in mixtures of DIOX and 2EE with different compositions were recorded on a Excalibur FTS300 Fourier-transform infrared spectrometer (Bio Rad Laboratories) with a solution cell SC-CaF-0.05 (GL Science, Japan) made of $\mathrm{CaF}_{2}$ and having $0.05-\mathrm{mm}$ path length. The conventional transmission method was used, and 500 times accumulations were performed at room temperature $\left(20-25^{\circ} \mathrm{C}\right)$ for each solution whose $c$ was about $3 \times 10^{-2} \mathrm{~g} \mathrm{~cm}^{-3}$. Additional measurements in pure DIOX and $2 \mathrm{EE}$ at higher polymer concentrations of about $6 \times 10^{-2} \mathrm{~g} \mathrm{~cm}^{-3}$ gave spectra ( $A$ relative to $c$ ) identical to those at $c \sim 3 \times 10^{-2} \mathrm{~g} \mathrm{~cm}^{-3}$, indicating negligible contributions from intermolecular interactions between polymer chains to IR spectra at $c$ below $6 \times 10^{-2} \mathrm{~g} \mathrm{~cm}^{-3}$.

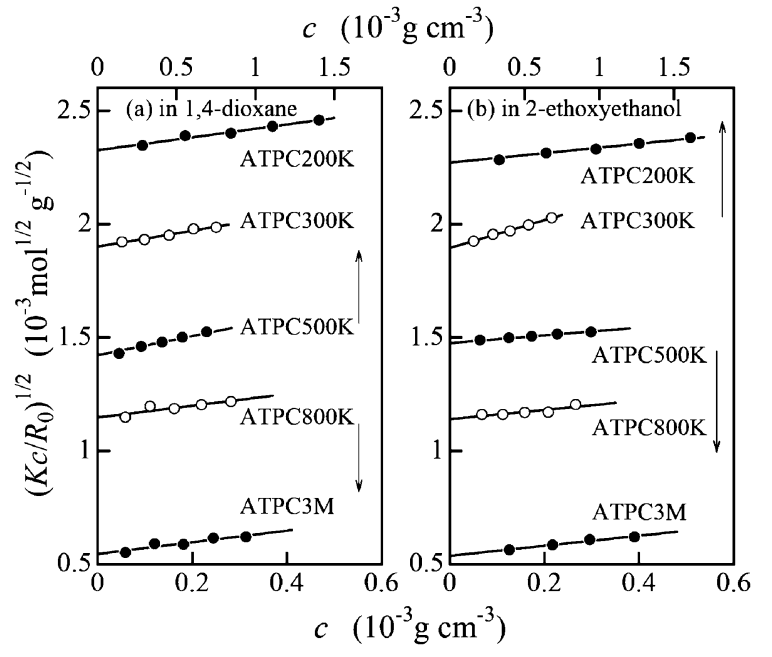

Figure 2. Concentration dependence of $\left(K c / R_{0}\right)^{1 / 2}$ for indicated ATPC samples in DIOX (a) and in $2 \mathrm{EE}$ (b) at $25^{\circ} \mathrm{C}$.

\section{RESULTS}

\section{Dimensional and Hydrodynamic Properties}

Figure 2 illustrates the concentration dependence of $\left(K c / R_{0}\right)^{1 / 2}$ for ATPC samples in the two solvents, where $R_{0}$ denotes $R_{\theta}$ at $\theta=0$. The indicated straight lines give $A_{2}$ values of $1-4 \times 10^{-4} \mathrm{~mol} \mathrm{~cm}^{3} \mathrm{~g}^{-2}$, showing that both DIOX and $2 \mathrm{EE}$ are good solvents for ATPC. The values of $M_{\mathrm{w}}$ determined in the two solvents agree with each other within $\pm 3 \%$, so that their averages are presented in Table I, along with the $A_{2}$ data. The table also includes $M_{\mathrm{w}}$ and $M_{\mathrm{z}} / M_{\mathrm{w}}$ from sedimentation equilibrium as well as $M_{\mathrm{w}} / M_{\mathrm{n}}$ determined by SEC-LS in tetrahydrofuran at $30^{\circ} \mathrm{C}$.

The angular dependence of $P(k)^{-1 / 2}$ is shown in Figure 3, in which the initial slopes indicated by the dashed lines and hence the radii of gyration for the respective samples are seen to be larger in DIOX than in 2EE. The values of $\left\langle S^{2}\right\rangle_{z}{ }^{1 / 2}$ determined are listed in Table I.

Figure 4 displays the $M_{\mathrm{w}}$-dependence of $\left\langle S^{2}\right\rangle_{\mathrm{z}}{ }^{1 / 2}$ and $[\eta]$ in DIOX at $25^{\circ} \mathrm{C}$, along with the relations reported by Burchard ${ }^{3}$ and Pfannemüller et al. ${ }^{11}$ The $[\eta]$ data of the three groups come fairly close to one another, whereas Burchard's $\left\langle S^{2}\right\rangle_{\mathrm{z}}$ data 

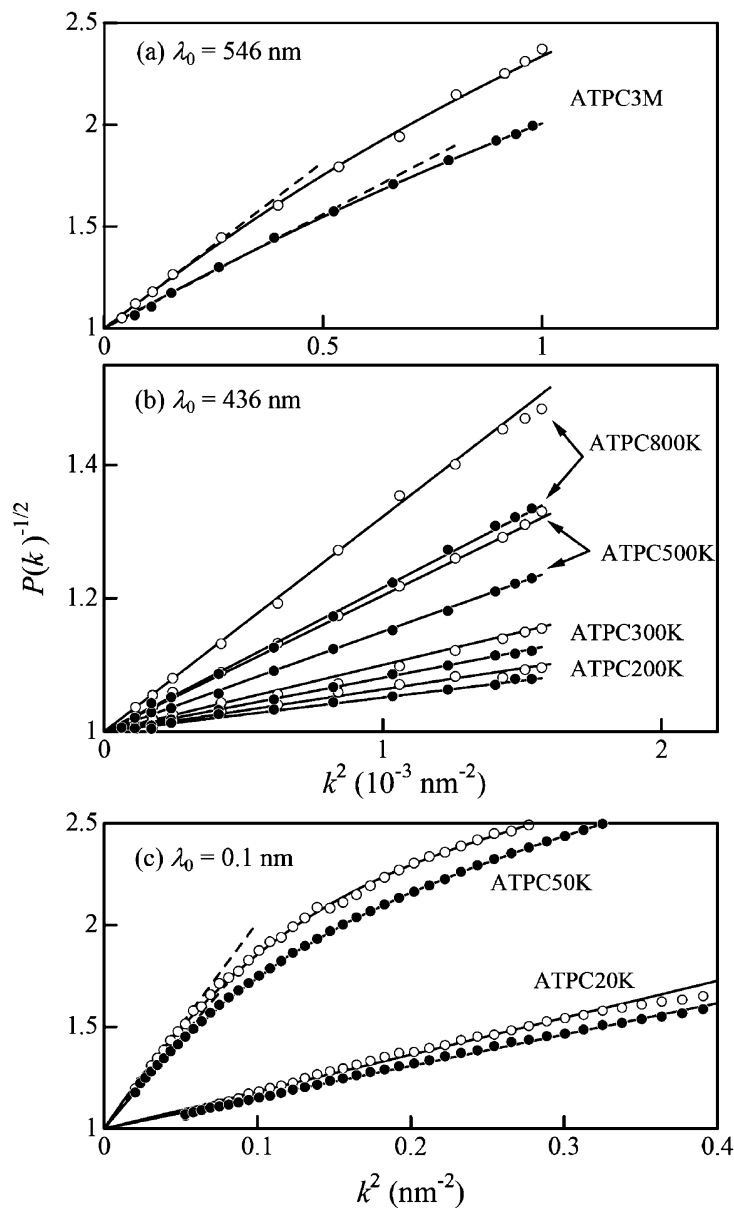

Figure 3. Berry plots for indicated ATPC samples in DIOX (open circles) and in $2 \mathrm{EE}$ (filled circles) at $25^{\circ} \mathrm{C}$. (a) $\lambda_{0}=546 \mathrm{~nm}$, (b) $\lambda_{0}=436 \mathrm{~nm}$, (c) $\lambda_{0}=0.1 \mathrm{~nm}$.

appear slightly above ours. The slopes of the curves fitting our $\left\langle S^{2}\right\rangle_{\mathrm{z}}{ }^{1 / 2}$ and $[\eta]$ data decrease from 0.74 to 0.55 and from 0.89 to 0.68 , respectively, with increasing $M_{\mathrm{w}}$, confirming the stiffchain behavior of ATPC. These physical properties in 2EE exhibit similar behavior (see Figures 7 and 9). Our numerical results of $[\eta]$ and $k^{\prime}$ in DIOX and 2EE have been summarized in Table I.

\section{IR and CD Spectra}

Figure 5a illustrates IR spectra for ATPC300K in mixtures of DIOX and 2EE with indicated volume fractions $x$ of 2EE. We assigned the double peaks at 1706 and $1754 \mathrm{~cm}^{-1}$ to the amide I band ${ }^{30}$ which depends remarkably on $x$ while the other peaks are almost independent of $x$. The amide I band reflects $\mathrm{C}=\mathrm{O}$ stretching, and the double peaks indicate the presence of, at least, two different $\mathrm{C}=\mathrm{O}$ groups in solution, that is, intramolecularly hydrogen bonding $\mathrm{C}=\mathrm{O}$ with $\mathrm{NH}$ (1706 $\mathrm{cm}^{-1}$; roughly $40 \%$ in amount) and virtually no or weakly interacting $\mathrm{C}=\mathrm{O}$ with some species $\left(1754 \mathrm{~cm}^{-1}\right)$. As $x$ increases, the peak height at the latter band lowers as a result of the appearance of a new peak between the two peaks. The third peak at $1725 \mathrm{~cm}^{-1}$ is clearly visible in the difference spectra (Figure 5b) obtained by subtracting $\varepsilon$ in DIOX

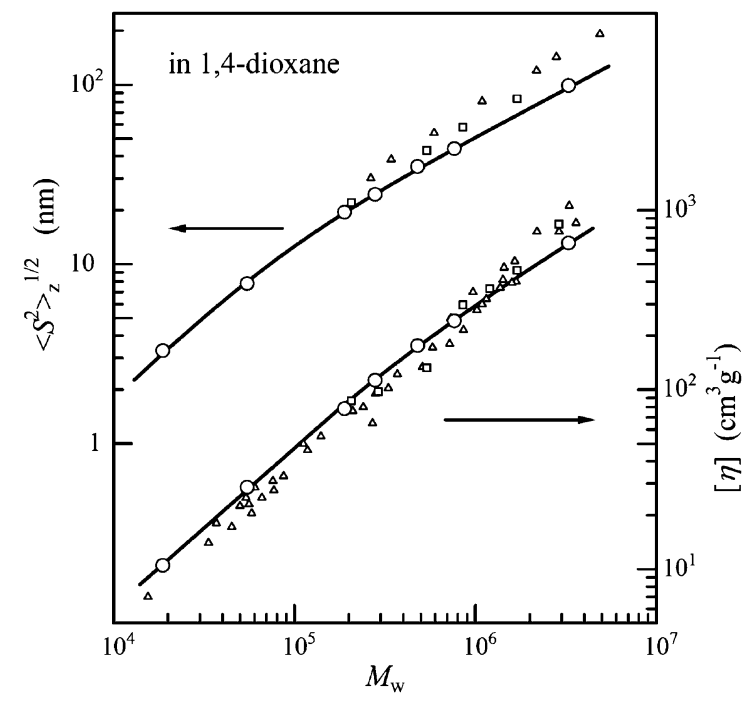

Figure 4. Molecular weight dependence of $\left\langle S^{2}\right\rangle_{z}{ }^{1 / 2}$ and [ $\left.\eta\right]$ for ATPC in DIOX at $25^{\circ} \mathrm{C}$ (circles), compared with earlier data by Burchard (triangles) and Pfannemüller et al..$^{11}$ (squares).
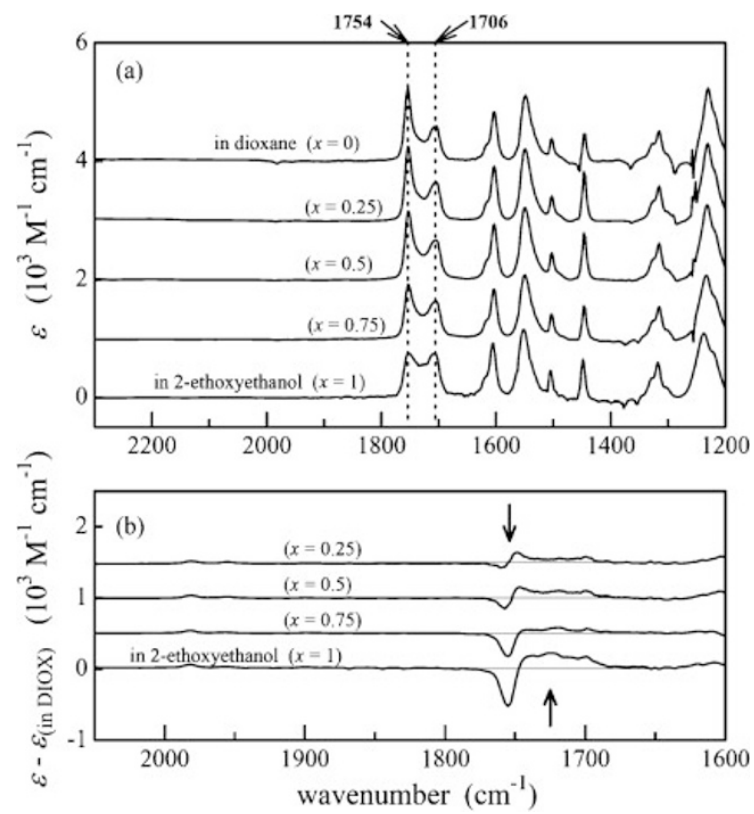

Figure 5. (a) IR spectra for sample ATPC $300 \mathrm{~K}$ in mixtures of DIOX and 2EE with indicated $x$ at room temperature $\left(20-25^{\circ} \mathrm{C}\right.$ ). (b) Difference spectra, obtained by subtracting $\varepsilon$ in DIOX from $\varepsilon$ for indicated $x$.

$\left(\varepsilon_{\text {(in DIOX) }}\right)$ from those in the indicated solvents. This new peak is most likely due to the formation of hydrogen bonds $-\mathrm{C}=\mathrm{O} \cdots \mathrm{HOC}_{2} \mathrm{H}_{4} \mathrm{OC}_{2} \mathrm{H}_{5}$. On the other hand, the shape and height of the peak at $1706 \mathrm{~cm}^{-1}$ are almost independent of $x$, indicating that the intramolecular hydrogen bonding is hardly affected by the presence of the hydroxyl group of $2 \mathrm{EE}$. We may conclude from these findings that on an average, about $40 \%$ of the $\mathrm{C}=\mathrm{O}$ groups in the ATPC molecule intramolecularly hydrogen bond to $\mathrm{NH}$ groups probably in the first and/or second nearest neighbor repeat units. 


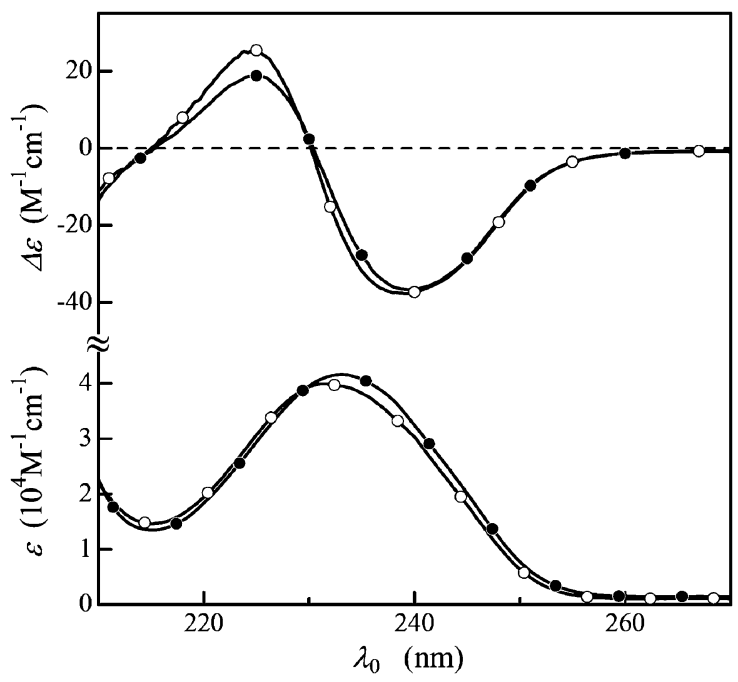

Figure 6. CD and UV spectra for sample ATPC300K in DIOX (open circles) and in $2 \mathrm{EE}$ (filled circles) at $25^{\circ} \mathrm{C}$.

Figure 6 shows that there is no substantial difference in CD and UV spectra between the two solvents. Thus the local conformations of ATPC in DIOX and 2EE must be essentially the same. The pronounced positive maximum and negative minimum around $\lambda_{0}=225$ and $240 \mathrm{~nm}$, respectively, may be taken to indicate that, as proposed by Bittiger and Keilich, ${ }^{4}$ the ATPC molecule should have locally regular or helical structure in the two solvents.

\section{DISCUSSION}

\section{Analysis of Scattering Data}

The unperturbed mean-square radius of gyration $\left\langle S^{2}\right\rangle_{0}$ of a wormlike chain may be expressed as ${ }^{31}$

$$
\left\langle S^{2}\right\rangle_{0}=\frac{L}{6 \lambda}-\frac{1}{4 \lambda^{2}}+\frac{1}{4 \lambda^{3} L}-\frac{1}{8 \lambda^{4} L^{2}}[1-\exp (-2 \lambda L)]
$$

where the contour length $L$ of the chain is related to the molar mass $M$ by

$$
L=M / M_{\mathrm{L}}
$$

with $M_{\mathrm{L}}$ being the molar mass per unit contour length. In the framework of the quasi-two-parameter (QTP) theory ${ }^{32-34}$ with the Domb-Barrett equation ${ }^{35}$ for the radius expansion factor $\alpha_{\mathrm{s}}$, $\left\langle S^{2}\right\rangle\left(\equiv\left\langle S^{2}\right\rangle_{0} \alpha_{\mathrm{s}}{ }^{2}\right)$ is described by $L, \lambda^{-1}$, and the excludedvolume strength $B$. These three parameters were determined by the trial and error method to be $M_{\mathrm{L}}=1550 \pm 70 \mathrm{~nm}^{-1}$, $\lambda^{-1}=24 \pm 3 \mathrm{~nm}$, and $B=1 \pm 1 \mathrm{~nm}$ in DIOX and $M_{\mathrm{L}}=$ $1590 \pm 70 \mathrm{~nm}^{-1}, \lambda^{-1}=18 \pm 2 \mathrm{~nm}$, and $B=0.8 \pm 0.8 \mathrm{~nm}$ in 2EE. In Figure 7, the calculated solid curves are seen to closely fit the data points. The excluded-volume effect in either solvent, that is, the difference between the solid and dashed curves, is quite small (less than $5 \%$ ) even at the highest $M_{\mathrm{w}}$ investigated.

Nakamura and Norisuye's theory ${ }^{36}$ for $P(k)$ of an unperturbed wormlike cylinder was applied to the SAXS data

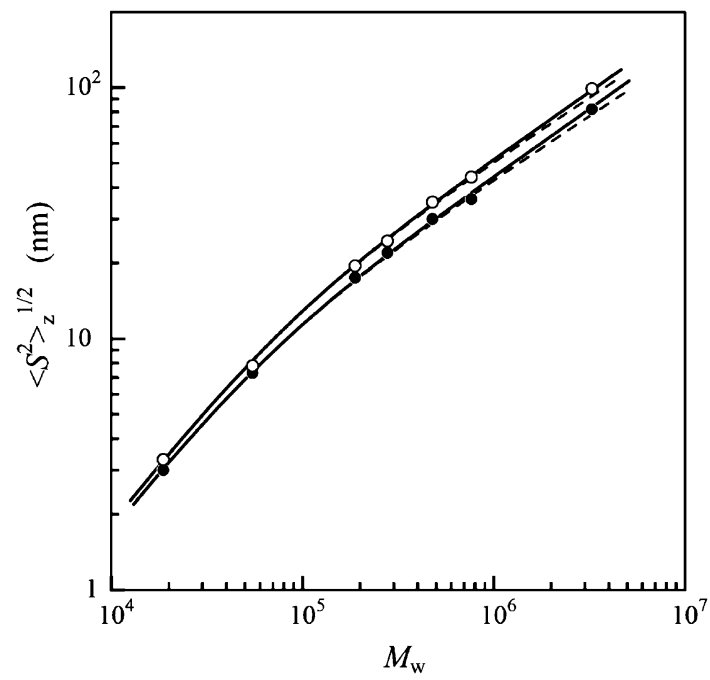

Figure 7. Comparison between the experimental $\left\langle S^{2}\right\rangle_{z}{ }^{1 / 2}$ for ATPC in DIOX (open circles) and in 2EE (filled circles) both at $25^{\circ} \mathrm{C}$ and the theoretical curves calculated from eq 2 for $\left\langle S^{2}\right\rangle_{0}$ and the DombBarrett equation ${ }^{35}$ for $\alpha_{\mathrm{s}}{ }^{2}$ in the QTP scheme ${ }^{32-34}$ with $M_{\mathrm{L}}=1550$ $\mathrm{nm}^{-1}, \lambda^{-1}=24 \mathrm{~nm}$, and $B=1 \mathrm{~nm}$ in DIOX and $M_{\mathrm{L}}=1590 \mathrm{~nm}^{-1}$, $\lambda^{-1}=18 \mathrm{~nm}$, and $B=0.8 \mathrm{~nm}$ in 2EE. Dashed lines show the theoretical values for $B=0$.

for ATPC50K, yielding $M_{\mathrm{L}}=1540 \mathrm{~nm}^{-1}, \lambda^{-1}=21 \mathrm{~nm}$, and $d=1.3 \mathrm{~nm}$ in DIOX and $M_{\mathrm{L}}=1640 \mathrm{~nm}^{-1}, \lambda^{-1}=15 \mathrm{~nm}$, and $d=1.4 \mathrm{~nm}$ in 2EE. The calculated solid lines of $k P(k)$ almost quantitatively reproduce the angular dependence of the experimental data, as shown in the two upper panels of Figure 8. The dashed curves calculated for the rod limit $\left(\lambda^{-1}=\infty\right)$ considerably differ from the solid ones around $k=0.3 \mathrm{~nm}^{-1}$. For ATPC20K, we obtained $M_{\mathrm{L}}=1500 \mathrm{~nm}^{-1}$ and $d=1.3 \mathrm{~nm}$ in DIOX and $M_{\mathrm{L}}=1580 \mathrm{~nm}^{-1}$ and $d=1.6$ $\mathrm{nm}$ in 2EE by assuming the above $\lambda^{-1}$ values for ATPC50K; we note that $\lambda^{-1}$ cannot be determined for ATPC20K because the theoretical solid lines fitting the data points in the two lower panels of the figure are hardly distinguishable from the corresponding dashed lines for the rod limit. In sum, the wormlike-chain parameters estimated from $P(k) \quad\left(M_{\mathrm{L}}=\right.$ $1520 \pm 20 \mathrm{~nm}^{-1}, \lambda^{-1}=21 \mathrm{~nm}$, and $d=1.3 \mathrm{~nm}$ in DIOX and $M_{\mathrm{L}}=1610 \pm 30 \mathrm{~nm}^{-1}, \lambda^{-1}=15 \mathrm{~nm}$, and $d=1.5 \pm 0.1 \mathrm{~nm}$ in 2EE) essentially agree with those from $\left\langle S^{2}\right\rangle_{\mathrm{z}}$ in the corresponding solvents. We note that the contribution $d^{2} / 8$ from the chain thickness to $\left\langle S^{2}\right\rangle$ of the cylindrical wormlike chain ${ }^{37}$ is at most $3.1 \%$ and hence negligible.

\section{Analysis of $[\eta]$ Data}

The intrinsic viscosity of a perturbed wormlike cylinder is given by the product of the unperturbed intrinsic viscosity $[\eta]_{0}$ and the cubic viscosity expansion factor $\alpha_{\eta}{ }^{3}$. The former, formulated by Yamakawa and Yoshizaki, ${ }^{38}$ may be expressed as

$$
[\eta]_{0}=\frac{f(\lambda L, \lambda d)}{\lambda^{3} M}
$$

For the latter, we use the Barrett equation ${ }^{39}$ in the QTP scheme, so that the four parameters, $M_{\mathrm{L}}, \lambda^{-1}, d$, and $B$, characterize $[\eta]$. 


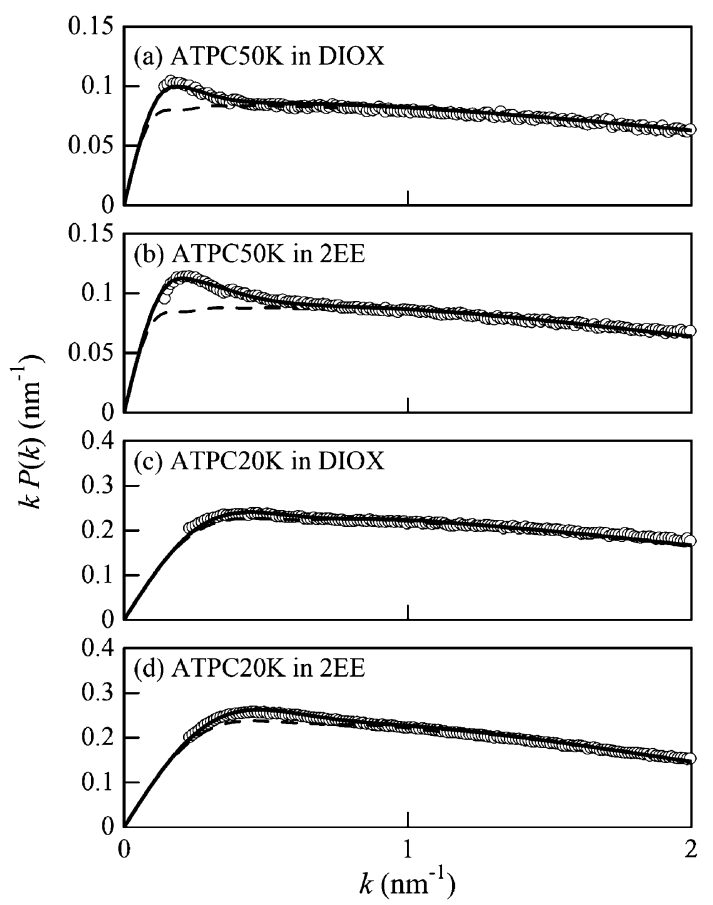

Figure 8. Holtzer plots for ATPC50K in DIOX (a) and in 2EE (b) and for ATPC20K in DIOX (c) and in $2 E E$ (d) at $25^{\circ} \mathrm{C}$. Solid curves, theoretical values for the unperturbed wormlike cylinder ${ }^{36}$ with the parameters given in the text. Dashed curves, theoretical values in the rod limit $\left(\lambda^{-1}=\infty\right)$

We analyzed the present $[\eta]$ data with $M_{\mathrm{L}}$ fixed to the mean from $P(k)$ and $\left\langle S^{2}\right\rangle_{\mathrm{z}}\left(1540\right.$ and $1600 \mathrm{~nm}^{-1}$ in DIOX and $2 \mathrm{EE}$, respectively); we note that the four parameters cannot uniquely be determined from the $[\eta]$ data. Figure 9 shows the molecular weight dependence of experimental $[\eta]$ to be almost quantitatively reproduced by the solid curves calculated with $\lambda^{-1}=20$ $( \pm 1) \mathrm{nm}, d=2.9( \pm 0.1) \mathrm{nm}$, and $B=0.5( \pm 0.5) \mathrm{nm}$ in DIOX and $\lambda^{-1}=14( \pm 1) \mathrm{nm}, d=2.8( \pm 0.1) \mathrm{nm}$, and $B=0.3$ $( \pm 0.3) \mathrm{nm}$ in $2 \mathrm{EE}$; each bracketed value indicates the uncertainty. The $\lambda^{-1}$ values in the two solvents are in substantial agreement with those determined from $P(k)$ and $\left\langle S^{2}\right\rangle_{\mathrm{z}}$. The discrepancy between the hydrodynamic $d$ from $[\eta]$ (2.8$2.9 \mathrm{~nm})$ and the statistical $d$ from $P(k)(1.3-1.5 \mathrm{~nm})$ may be taken to reflect the electron density profile around the ATPC chain contour in solution. ${ }^{34,40,41}$

\section{Chain Stiffness and Local Conformation}

The wormlike-chain parameters obtained from the three physical properties, $\left\langle S^{2}\right\rangle_{\mathrm{z}}, P(k)$, and $[\eta]$, are summarized in Table II, where $h$ has been calculated from $h=M_{0} / M_{\mathrm{L}}$. The values of $\lambda^{-1}$ (the Kuhn length or more generally the stiffness parameter in the helical wormlike chain ${ }^{34}$ ) in the two solvents are much larger than that for amylose in dimethylsulfoxide $\left(\lambda^{-1}=4 \mathrm{~nm}\right)$ and comparable to that for cellulose tris(phenylcarbamate) in tetrahydrofuran $\left(\lambda^{-1}=21 \mathrm{~nm}\right) .{ }^{42}$ This high stiffness of ATPC compared to amylose may be ascribed to the intramolecular hydrogen bonding between the $\mathrm{C}=\mathrm{O}$ and $\mathrm{NH}$ groups as well as the high substituent density. The present IR spectra (Figure 5a) demonstrate the presence of intramolecular

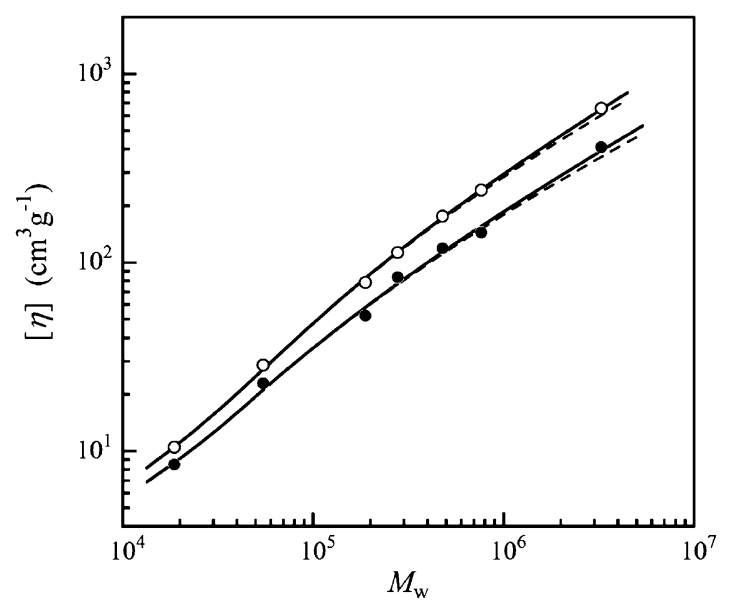

Figure 9. Comparison between the experimental [ $\eta$ ] for ATPC in DIOX (open circles) and in $2 \mathrm{EE}$ (filled circles) both at $25^{\circ} \mathrm{C}$ and the theoretical curves calculated from eq 4 for $[\eta]_{0}$ and the Barrett equation ${ }^{39}$ for $\alpha_{\eta}{ }^{3}$ in the QTP scheme with $M_{\mathrm{L}}=1540 \mathrm{~nm}^{-1}, \lambda^{-1}=20 \mathrm{~nm}$, $d=2.9 \mathrm{~nm}$, and $B=0.5 \mathrm{~nm}$ in DIOX and $M_{\mathrm{L}}=1600 \mathrm{~nm}^{-1}$, $\lambda^{-1}=14 \mathrm{~nm}, d=2.8 \mathrm{~nm}$, and $B=0.3 \mathrm{~nm}$ in 2EE. Dashed lines show the theoretical values for $B=0$.

Table II. Wormlike chain parameters for ATPC at $25^{\circ} \mathrm{C}$

\begin{tabular}{ccccc}
\hline Solvent & $h(\mathrm{~nm})$ & $\lambda^{-1}(\mathrm{~nm})$ & $d(\mathrm{~nm})^{\mathrm{a}}$ & $d(\mathrm{~nm})^{\mathrm{b}}$ \\
\hline DIOX & $0.34 \pm 0.01$ & $22 \pm 2$ & 1.3 & $2.9 \pm 0.1$ \\
2EE & $0.32 \pm 0.01$ & $16 \pm 2$ & 1.5 & $2.8 \pm 0.1$ \\
\hline
\end{tabular}

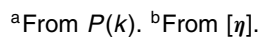

hydrogen bonds in DIOX and 2EE. Since the proton donor ability of the latter solvent is higher than that of the former, we may interpret the slightly smaller $\lambda^{-1}$ in $2 \mathrm{EE}$ as due to fewer intramolecular hydrogen bonds between the $\mathrm{NH}$ and $\mathrm{C}=\mathrm{O}$ groups of ATPC. However, such a subtle difference in hydrogen bonding cannot be observed from the present IR spectra. On the other hand, the exciton splitting in the CD spectra of ATPC (Figure 6) substantiates the significance of the substituent effect because the CD spectra indicate the dense and regularly (or helically) allocated phenyl groups near the main chain.

The estimated values of $h$ in DIOX and 2EE in Table II are substantially the same and both $(0.33 \pm 0.02 \mathrm{~nm})$ are smaller than $0.37-0.40 \mathrm{~nm}$ known for amylosetriesters in the crystalline state. ${ }^{18,43}$ This seems consistent with the IR and CD spectra showing the presence of intramolecular hydrogen bonds and locally regular structure. It should be noted that the $h$ values in the two solvents can be smaller by about $10 \%$ if the polydispersity correction is made for $\left\langle S^{2}\right\rangle_{\mathrm{z}}$ with $M_{\mathrm{z}} / M_{\mathrm{w}} \sim 1.1$.

Conformational energy maps for both amylose ${ }^{44,45}$ and amylose tris(3,5-dimethylphenylcarbamate) ${ }^{46}$ have a shallow minimum which allows the left handed helices with various $h$ values. This indicates that $h$ of the amylosic chain may be influenced by a small perturbation, i.e., intramolecular hydrogen bonding, intermolecular hydrogen bonding with solvent molecules, and packing of substituents and solvent molecules, and thus must be susceptible to such effects. Nonetheless, 
we find that the $h$ values for ATPC in the two solvents happen to be essentially the same. It is intriguing to investigate $h$ of ATPC in various solvents and also of other amylose derivatives in relation to their local conformation and chain stiffness.

\section{CONCLUSIONS}

The contour length $h$ per repeating unit for amylose tris(phenylcarbamate) (ATPC) is $0.33 \pm 0.02 \mathrm{~nm}$ in 1,4 -dioxane (DIOX) and in 2-ethoxyethanol (2EE). This value is 10$20 \%$ smaller than those for amylosetriesters probably due to the intramolecular hydrogen bonding between $\mathrm{C}=\mathrm{O}$ and $\mathrm{NH}$ groups of the neighbor glucose units, detected from the split amide I band. The locally regular or helical conformations as indicated by $\mathrm{CD}$ are essentially the same in the two solvents. The Kuhn segment length (or more generally the stiffness parameter in the helical wormlike chain) is much higher $(22 \pm 2 \mathrm{~nm}$ in DIOX and $16 \pm 2 \mathrm{~nm}$ in $2 \mathrm{EE})$ than that $(4 \mathrm{~nm})$ of amylose in dimethylsulfoxide due to the combination effect of the intramolecular hydrogen bonding and high segment density of phenyl carbamate groups.

Acknowledgment. We are grateful to Professors Kenji Okuyama (Osaka University) and Yo Nakamura (Kyoto University) for their help in SAXS measurements and data analysis, Professor Tadashi Inoue (Osaka University) for FT-IR measurements, and Professor Takahiro Sato (Osaka University) for fruitful discussions. We also thank Ezaki Glico Co. for providing amylose samples. The synchrotron radiation experiments were performed at the BL40B2 in SPring-8 with the approval of the Japan Synchrotron Radiation Research Institute (JASRI) (Proposal \#2007A1034 and \#2007B1296).

Received: September 27, 2008 Accepted: November 21, 2008

Published: January 15, 2009

\section{REFERENCES}

1. W. Burchard, Z. Physik. Chem., 42, 293 (1964).

2. J. M. G. Cowie, Biopolymers, 3, 69 (1965).

3. W. Burchard, Makromol. Chem., 88, 11 (1965).

4. H. Bittiger and G. Keilich, Biopolymers, 7, 539 (1969).

5. a) W. Banks, C. T. Greenwood, and J. Sloss, Makromol. Chem., 140, 109 (1970).

b) W. Banks, C. T. Greenwood, and J. Sloss, Makromol. Chem., 140, 119 (1970).

6. W. Banks and C. T. Greenwood, Makromol. Chem., 144, 135 (1971).

7. W. Banks, C. T. Greenwood, and J. Sloss, Eur. Polym. J., 7, 879 (1971).

8. W. Burchard, Br. Polym. J., 3, 214 (1971).

9. W. Sutter and W. Burchard, Makromol. Chem., 179, 1961 (1978).
10. A. K. Gupta, E. Marchal, W. Burchard, and B. Pfannemüller, Macromolecules, 12, 281 (1979).

11. B. Pfannemüller, M. Schmidt, G. Ziegast, and K. Matsuo, Macromolecules, 17, 710 (1984).

12. Y. Muroga, K. Hayashi, M. Fukunaga, T. Kato, S. Shimizu, and K. Kurita, Biophys. Chem., 121, 96 (2006).

13. Y. Nakanishi, T. Norisuye, A. Teramoto, and S. Kitamura, Macromolecules, 26, 4220 (1993).

14. T. Norisuye, Polym. J., 26, 1303 (1994).

15. Y. Okamoto and E. Yashima, Angew. Chem., Int. Ed., 37, 1020 (1998).

16. C. Yamamoto and Y. Okamoto, Bull. Chem. Soc. Jpn., 77, 227 (2004).

17. O. Kratky and G. Porod, Recl. Trav. Chim. Pays-bas, 68, 1106 (1949).

18. P. Zugenmaier and H. Steinmeier, Polymer, 27, 1601 (1986).

19. S. Kitamura, H. Yunokawa, S. Mitsuie, and T. Kuge, Polym. J., 14, 93 (1982).

20. S. Kitamura, K. Kobayashi, H. Tanahashi, T. Ozaki, and T. Kuge, Denpun Kagaku (J. Jpn. Soc. Starch Sci.) 36, 257 (1989).

21. S. Kitamura, in "The Polymeric Materials Encyclopedia, Synthesis, Properties and Applications," J. C. Salamone, Ed., CRC Press: New York, 1996; Vol. 10, p 7915.

22. H. Waldmann, D. Gygax, M. D. Bednarski, W. R. Shangraw, and G. M. Whitesides, Carbohydr. Res., 157, C4 (1986).

23. Gj. Deželić and J. Vavra, Croat. Chem. Acta, 38, 35 (1966).

24. D. N. Rubingh and H. Yu, Macromolecules, 9, 681 (1976).

25. G. C. Berry, J. Chem. Phys., 44, 4550 (1966).

26. T. Norisuye, T. Yanaki, and H. Fujita, J. Polym. Sci. Polym: Phys. Ed., 18, 547 (1980).

27. M. L. Huggins, J. Am. Chem. Soc., 64, 2716 (1942).

28. D. F. Mead and R. M. Fuoss, J. Am. Chem. Soc., 64, 277 (1942).

29. F. W. Billmeyer Jr., J. Polym. Sci., 4, 83 (1949).

30. R. B. Kasat, Y. Zvinevich, H. W. Hillhouse, K. T. Thomson, N.-H. L. Wang, and E. I. Franses, J. Phys. Chem. B., 110, 14114 (2006).

31. H. Benoit and P. Doty, J. Phys. Chem., 57, 958 (1953).

32. H. Yamakawa and W. H. Stockmayer, J. Chem. Phys., 57, 2843 (1972).

33. J. Shimada and H. Yamakawa, J. Chem. Phys., 85, 591 (1986).

34. H. Yamakawa, "Helical Wormlike Chains in Polymer Solutions," Springer, Berlin, 1997.

35. C. Domb and A. J. Barrett, Polymer, 17, 179 (1976).

36. Y. Nakamura and T. Norisuye, J. Polym. Sci. Part B: Polym. Phys., 42, 1398 (2004).

37. T. Konishi, T. Yoshizaki, T. Saito, Y. Einaga, and H. Yamakawa, Macromolecules, 23, 290 (1990).

38. H. Yamakawa and T. Yoshizaki, Macromolecules, 13, 633 (1980).

39. A. J. Barrett, Macromolecules, 17, 1566 (1984).

40. P. Hickl, M. Ballauff, U. Scherf, K. Müllen, and P. Lindner, Macromolecules, 30, 273 (1997).

41. K. Terao, K. Mizuno, M. Murashima, Y. Kita, C. Hongo, K. Okuyama, T. Norisuye, and H. P. Bächinger, Macromolecules, 41, 7203 (2008).

42. F. Kasabo, T. Kanematsu, T. Nakagawa, T. Sato, and A. Teramoto, Macromolecules, 33, 2748 (2000).

43. Y. Takahashi and S. Nishikawa, Macromolecules, 36, 8656 (2003).

44. C. V. Goebel, W. L. Dimpfl, and D. A. Brant, Macromolecules, 3, 644 (1970).

45. J. Shimada, H. Kaneko, T. Takada, S. Kitamura, and K. Kajiwara, J. Phys. Chem. B., 104, 2136 (2000).

46. C. Yamamoto, E. Yashima, and Y. Okamoto, J. Am. Chem. Soc., 124, 12583 (2002) 